\title{
gradsCOOL: A Learning Management System for Bulacan State University Graduate School
}

\author{
Raquel C. Adriano ${ }^{1+}$ and Marian Minneli S. Cruz ${ }^{2}$ \\ ${ }^{1}$ Faculty, BulSU Graduate School and College of Information \& Communications Technology, Bulacan \\ State University, City of Malolos Bulacan, Philippines \\ ${ }^{2}$ Faculty, BulSU Graduate School and College of Information \& Communications Technology , Bulacan \\ State University, City of Malolos Bulacan, Philippines
}

\begin{abstract}
Information and Communication Technology (ICT) plays a vital role in the curriculum design of the various educational institutions. It provides vital ways to improve the teaching and learning approach, making available resources easy to share and acquire. The major problem of the study was to develop learning management system for the Graduate School of Bulacan State University. It made use of ADDIE system development model, which consists of five phases: (1) analysis; (2) design; (3) development; (4) implementation; and (5) evaluation. Significantly, gradsCOOL (graduate school COllaborative Outcomebased Learning) is a Learning Management System (LMS) characterized by the following essential features: (1) centralized learning management; (2) mobile learning; (4) course management; and (5) tracking and reporting. Its acceptability was examined from multiple perspectives with respect to its (1) functionality; (2) reliability; (3) usability; (4) maintainability; and (5) portability. Moreover, considering learning management system as an important factor in successful ICT implementation in Higher Education Institutions (HEIs) setting, with the incorporated significant features and the acceptability of the software, it was recommended that this new mode of instruction be implemented in Graduate School of Bulacan State University. The adoption of the developed LMS into teaching and learning is of great importance as the school moves towards changing its delivery method to include a component of online learning, enhancing the delivery of instruction achieving better outcomes.
\end{abstract}

Keywords: Learning Management System, Centralized Learning Management, Mobile Learning, Course Management, Tracking and Reporting, and ADDIE Model

\section{Introduction}

Information and Communication Technology (ICT) plays a significant role in the curriculum design of the various educational institutions. It provides means to access, share and acquire huge amount of information enhancing the knowledge of both teachers and students.

Technological advances in ICT led to the development of e-learning systems that can be used as a teaching and learning approach. E-learning make education accessible at a relatively low cost compared with traditional setting. It provides every institution the flexibility of time and place of lesson delivery. It makes use of technological tools to enable learners study anytime and anywhere. It enhances students' motivation to learning as well as promotes exchange of different views [1].

The integration of e-learning with traditional classroom instruction defines blended learning which is expected to enhance the face-to-face instruction. Blended learning is no more about reshaping and enhancing the traditional classroom than it is about making e-learning more acceptable. It integrates the best features of both methodologies creating a unique combination of synchronous and asynchronous, direct and mediated modes of communication [2]. Blended learning enhances learning as it combines modern communications

\footnotetext{
${ }^{+}$Corresponding author: Raquel Concepcion Adriano Tel: + 639228111640

E-mail address: raquel.adriano@bulsu.edu.ph
} 
and information technology with traditional mode encouraging the student's desire and increasing their interest to learn through the form that is best suited to the student without considering alternative methods.

The challenge of integrating Learning Management System (LMS) into teaching and learning highlights the complexities involved in blended-learning environments. Incorporating blended learning requires a more holistic understanding of how diverse modes of teaching coexist - whether on-line or in class to guide, enhance and support student learning. Hence, the challenge lies not within the technology itself, but in rethinking course design and developing a sense of fluidity in teaching and learning with technology [3]. By building on principles of good teaching and drawing on users' (students and instructors) experiences in hybrid ways of learning, one can rethink how LMSs fit within the learning environment.

In an educational context, Learning Management Systems (LMSs) are internet based, software that allows to manage lesson materials, lesson tasks, communication and other aspects of instructions for the course [4]. It provides mechanism to facilitate effective communication between students and teachers exposing to different learning challenges. LMSs have become an integral part of the educational systems, increasing the interest of most universities in in hybrid approaches that blend in class and online learning [5]. It provides possible avenue for an easy access and sharing of classroom materials. It is considered a portal for lecturers and students interactions out of the classroom, through forum discussions minimizing time spent in the traditional classroom setting [6].

The Graduate School of Bulacan State University aims to train students at an advanced level in specific fields of study in order for them to continue graduate studies or to meet professional goals. It is committed to provide opportunities for continued professional growth and development in various discipline, exposing to innovative methods focusing on research. Currently, the graduate school is utilizing traditional teaching approaches. However, it understands the need for an innovative learning approach thus committing itself to online education by developing a wide variety of high-quality, online and blended programs that are handled by a pool of highly qualified faculty. The adoption of the developed LMS into teaching and learning is of great importance as the school moves towards changing its delivery method to include a component of online learning, enhancing the delivery of instruction achieving better outcomes.

\subsection{Statement of the problem}

The major concern of the study is to develop a Learning Management System (LMS) for the Graduate School of Bulacan State University. Specifically, the study sought answers to the following questions:

What are the significant features of the LMS for BulSU-GS?

What design model may be utilized in developing the LMS?

How acceptable is LMS for in terms of functionality, reliability, usability, maintainability, portability?

\subsection{Significance of the study}

The results of the study would be very useful to the institution in the sense that it would facilitate innovative teaching and learning.

The system will provide insights to the BulSU Administrators on the importance of Learning Management System in education, a system that is scalable and an inexpensive solution promoting teaching and paperless instruction. It has the capability that may be used by faculty members in disseminating instructional materials such syllabus, course outline, lessons, assignments, examinations, grades, announcements and forums. The online access capability of the system may be used by students in viewing their course outline, lessons, assignments, grades and announcements by logging with their respective user's account and password to the database.

Furthermore, the developed LMS would be very useful for the continual improvement of online instruction.

\subsection{Scope and Delimitation of the study}

The study focused on the development of Learning Management System. Computer networks and Web browser are utilized for sharing services and resources. The implementation of the system is suite of tools to enhance teaching by taking advantage of the online learning blended with traditional teaching approach 
The development process covers analysis, design, development, implementation, and evaluation. It is an expressed limitation of the study that the evaluation of the acceptability of the system will be done through perceptual evaluation using the criteria: (1) functionality; (2) reliability; (3) usability; (4) maintainability; and (5) portability.

\section{Methodology}

The system was developed using the ADDIE Model, which consists of the following five phases: (1) analysis; (2) design; (3) development; (4) implementation; and (5) evaluation.

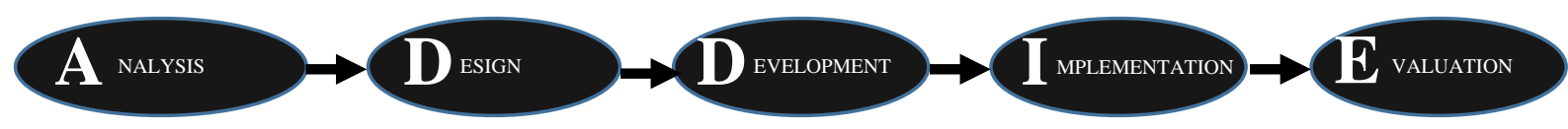

Fig. 1: The ADDIE Model

Phase I - Analysis Phase. The aim of analysis phase is to determine clearly the details of each requirement producing a user-oriented description of what is expected on the developed system. A requirement specification has been created which includes identification for whom the software is to be developed, the software environment, its constraints, instructional contents, goals and objectives. A thorough analysis of the problem requirements and careful understanding of the goals and objectives were carried out by the researchers in this phase.

Phase II - Design Phase. In this phase the system design is prepared based on the requirements specification. Design models were constructed depicting the hierarchical structure of the system modules and its interaction. This phase helped to identify the hardware and software requirements defining the overall system architecture which includes input requirements, interfaces, files and databases, system processing, system controls, backup and output requirements.

Phase III - Development Phase. In this phase, the data collected from the two previous phases were used to construct the interactive prototype of the software. After designing the structural components of the software, the design plan was translated into computer programs utilizing different software development tools. In this phase, the researchers made use of the data collected from the two previous phases and use this information to construct that program that will relay what needs to be incorporated.

Phase IV - Implementation Phase. After the code has been developed, the program was tested to verify that each function operates in conformance with the requirements defined in the previous phases. During this first round of testing known as unit testing, the program is submitted to assessments that focus on specific units or components of the software to determine whether each one is fully functional. It was then followed by an integration testing to combine all of the units within a program and test them as a group, identifying possible defects between modules/functions.

Phase $\boldsymbol{V}$ - Evaluation Phase. It is the process that determines the validates quality of the final output. It is an on-going activity conducted at such phase of ADDIE model. It is used to determine whether the objectives have been met and to identify those parts were modifications are required. A User Acceptance Testing (UAT) was done also known as beta or end-user testing to determine the software acceptability. This is the final testing performed once the functional, system and regression testing are completed. It made use of a validated questionnaire for the evaluation of the acceptability of the LMS using the pool judgements of IT Experts, faculty members and selected graduate school students which was based on (1) functionality; (2) reliability; (3) usability; (4) maintainability; and (5) portability.

\section{Result and Discussion}

\subsection{Significant Features of the Learning Management System}

The gradsCOOL-LMS includes multiple features which provides online tools and environment for course interactions, such as: (1) Centralized Learning Management;(2) Mobile Learning; (3) Course 
Management; and (4) Tracking and Reporting. It will make teaching and course management easier by providing a framework and set of tools for instructors.

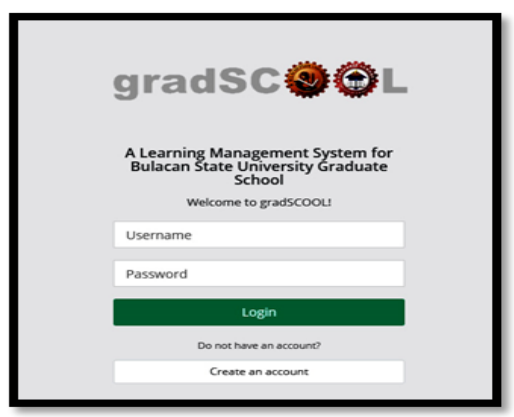

Fig. 2: User Log in.

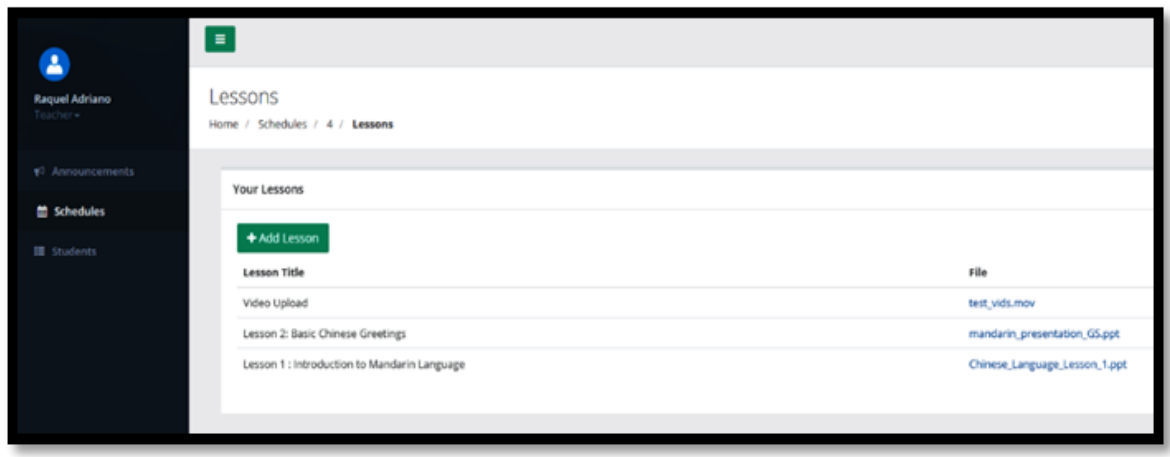

Fig. 3: Faculty Module for uploading of course materials such as course syllabus, lesson content and task/assignments.

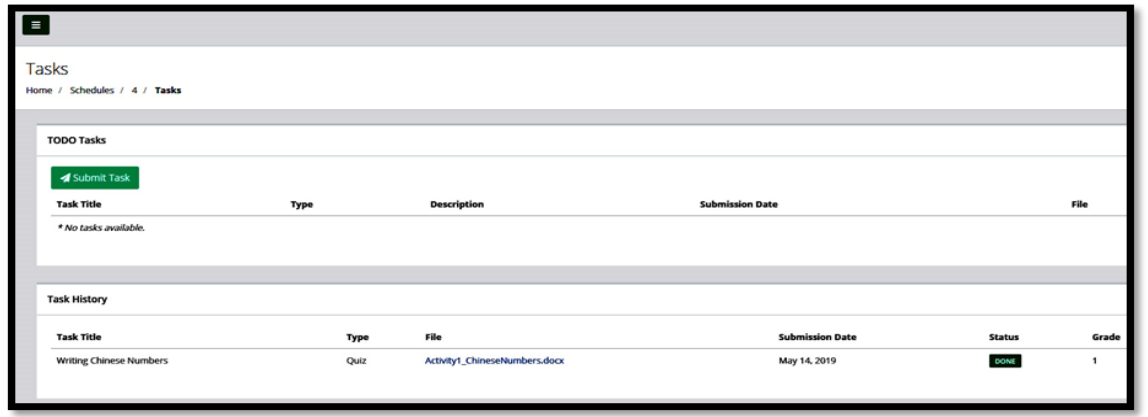

Fig. 4: Student Module for task submissions and report of grades.

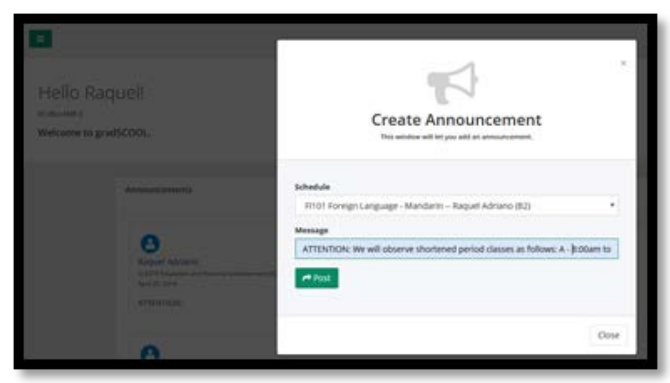

Fig. 5: Posting of Announcement.

Centralized Learning Management. The gradsCOOL-LMS will bring sources, material, learners, and instructors all under the same roof, providing them a virtual learning environment they can access regardless of their location. In such away, instructors can upload course content and evaluate performance in a more consistent manner.

Course Management. This is the feature that enables the instructors to upload the, course syllabus, course content and course requirements, manage course calendars by updating course settings like date of completion and generate grade reports. 
Mobile Learning. The delivery of learning materials in the LMS supports the use of mobile devices like a phone or a tablet. Smartphones and tablets are radically transforming how we access content and stay connected. Data is being consumed at a rapid pace on mobile devices and education is getting infused with our daily routine. Mobile learning takes online education right to the student, making it their choice and not the teachers' choice.

Tracking and Reporting. The LMS provides an area for creating detailed reports of important data such as grade reports and outcome reports, missing work, class status, task completion.so that the students may view their grades on the submitted assignments and activities.

\subsection{Level of Acceptability of the Learning Management System}

Acceptance testing were done to evaluate the system's compliance with respect to user needs, requirements, and processes and whether it is acceptable for implementation. The software was presented in a panel of examiners composed of three (3) IT experts and two (2) faculty members of the graduate school. The IT experts are technical people who validated the software against the functional specifications while the faculty members are education specialist who are considered the end-users. Observations and suggestions of the panel were gathered for possible enhancements of the software. The gradsCOOL-LMS was then tested in an actual class composed of 25 students in the graduate school. Both panel of examiners and students made use of a validated questionnaire and based their evaluations on the following criteria: (1) functionality; (2) reliability; (3) usability; (4) maintainability; and (5) portability. Evaluations were quantified using a fivepoint Likert scale interpreted in Table 1.

Table 1: Five-point Likert Scale used in Evaluating the Level of Acceptability.

\begin{tabular}{ccc}
\hline Scale & Weighted Mean & Descriptive Equivalent \\
5 & $4.50-5.00$ & Very Good \\
4 & $3.50-4.49$ & Good \\
3 & $2.50-3.49$ & Fair \\
2 & $1.50-2.49$ & Poor \\
1 & $1.00-1.49$ & Very Poor \\
\hline
\end{tabular}

Table 2: Summary of Experts, Faculty and Students Evaluation on the Level of Acceptability of the Learning Management System.

\begin{tabular}{|c|c|c|c|c|}
\hline Indicators & \multicolumn{3}{|c|}{ Evaluations } & $\begin{array}{c}\text { Verbal } \\
\text { Interpretation }\end{array}$ \\
\hline $\begin{array}{l}\text { Functionality } \\
\text { Reliability } \\
\text { Usability } \\
\text { Maintainability } \\
\text { Portability }\end{array}$ & $\begin{array}{c}\text { IT } \\
\text { Experts/Faculty } \\
4.68 \\
4.55 \\
4.65 \\
4.53 \\
4.52\end{array}$ & $\begin{array}{c}\text { Students } \\
4.68 \\
4.64 \\
4.62 \\
4.62 \\
4.58\end{array}$ & $\begin{array}{c}\text { Mean } \\
4.68 \\
4.60 \\
4.63 \\
4.58 \\
4.55\end{array}$ & $\begin{array}{l}\text { Very Good } \\
\text { Very Good } \\
\text { Very Good } \\
\text { Very Good } \\
\text { Very Good }\end{array}$ \\
\hline \multicolumn{3}{|c|}{ Overall Mean } & 4.61 & Very Good \\
\hline
\end{tabular}

Table 2 shows that the gradsCOOL-LMS was rated with a very good rating in terms of functionality with a mean of (4.68) which means functions are appropriate and correct to specifications, software can interact with other components and provides security requirements.

In terms of reliability, the evaluators rated the system very good with a mean of (4.60) which means the system has the ability to withstand and recover from component failure, it has the ability to bring back failed system to full operation, including data and network connections and has the ability to produce correct computations, output or reports.

The usability of the system was rated "very good "with a mean of (4.63) in terms of the following indicators: understandability, ease of which systems functions can be understood; learnability, learning effort for different users; and operability, ability of the software to be easily operated by a given user in a given environment. 
The data gathered from the evaluations of the experts of its maintainability portray a rating of very good and a mean of (4.58). This was based on the following indicators: analyzability, ability to identify the root cause of a failure within the software; changeability, software adjusts well to different screen dimensions, color depths, and font sizes; and stability, characterizes the sensitivity to change of a given system.

One of the elements of a software is its portability which was rated "very good" with a mean of (4.55), which was based on its adaptability, ability of the system to change to new specifications or operating environments; install ability, is software easy to install; replaceability, ease of exchanging a given software component within a specified environment and system coupling; software compatibility, provision for portability of operating system used; and build environment portability, absence of other software requirement such as runtime system or standard database management engine.

The gradsCOOL Learning Management System as a whole was found acceptable as shown by the grand mean of (4.61) and was strongly recommended for adoption and for further improvement of the software.

\section{Conclusions}

On the basis of significant findings, the following conclusions were drawn:

- The implementation of the gradsCOOL Learning Management System (LMS) will be a great help in improving the current teaching and learning approach of the graduate school.

- The gradsCOOL-LMS includes multiple features which provides an online tools and environment for course interactions, such as centralized learning management, course management, mobile learning, tracking and reporting.

- The gradsCOOL-LMS was developed using the ADDIE (Analysis, Design, Development, Implementation, and Evaluation) model.

- The gradsCOOL-LMS was highly acceptable in terms of functionality, reliability, usability, maintainability and portability.

\section{Acknowledgement}

The researchers would like to express their gratitude to the faculty members \& students of the College of Information and Communications Technology and Graduate School of Bulacan State University for the kind support and help.

Also thanks and appreciations to their family, colleagues and friends who supported them for the completion of this paper.

\section{References}

[1] J.K. Smedley. Modelling the impact of knowledge management using technology . OR Insight (2010) 23, 233250.

[2] D.R Garrison and N.D. Vaughan. Blended learning in higher education. San Francisco: Jossey-Bass.2008.

[3] D. E.Bair and M. A. Bair Paradoxes of online teaching. International Journal for the Scholarship of Teaching and Learning, 5(2), 1-15.2011.

[4] B. Abu Shawar,. Learning Management System and its Relationship with Knowledge Management. In: Faculty of Computer \& Information science, Ain Sham University, 4th International Conference on Intelligent Computing and Information Systems. Cairo, Egypt March 19-22, 2009.

[5] Jamal ,Hala and Ameera Shanaah. The Role of Learning Management Systems in Educational Environments: An Exploratory Case Study . Linnaaeus University, http://nu.divaportal.org/smash/get/diva2:435519/FULLTEXT01.pdf 2011.

[6] Nor Azura Adzharuddin and Lee Hwei Ling, Learning Management System (LMS) among University Students: Does It Work? International Journal of e-Education, e-Business, e-Management and e-Learning, Vol. 3, No. 3, June 2013. 